\title{
U.S. Trade and Inventory Dynamics
}

\author{
By George Alessandria, Joseph P. Kaboski, Virgiliu Midrigan*
}

We examine the substantial drop and rebound in international trade by the U.S. ${ }^{1}$ in the period 2008 to 2010, which was large relative to the movements in either production or absorption of traded goods. From July 2008 to February 2009 U.S. real imports and exports each fell by about 24 percent while manufacturing production fell 12 percent. The rebound was equally impressive, with imports and exports expanding about 20 percent between May 2009 and May 2010 while manufacturing production rebounded only by 10 percent. $^{2}$ These relatively large movements in trade only arise in standard trade models when trade costs rise and fall substantially. ${ }^{3}$

The alternative hypothesis we explore here and in a companion paper (George Alessandria, Joseph P. Kaboski, and Virgiliu Midrigan, 2010b) is that the magnified movements in international trade reflect a severe adjustment of inventory holdings of firms. Since our aim is to understand the large excess drop in trade relative to either sales or domestic production, we emphasize that these adjustments are larger for firms involved in international transactions. We have argued, in Alessandria, Kaboski and Midrigan (2010a), that the frictions involved in international transactions - namely delivery lags and economies of scale in transaction costs -

\footnotetext{
* Alessandria: Senior Economic Advisor and Economist, Research Department, Federal Reserve Bank of Philadelphia, Ten Independence Mall, Philadelphia, PA 19106 (George.Alessandria@phil.frb.org); Kaboski: Associate Professor, Department of Economics, 434 Flanner Hall, University of Notre Dame, Notre Dame, IN 46556 (jkaboski@nd.edu). Midrigan: Assistant Professor, Economics Department, New York University, 9 W. 4th Street, 6FL, New York, NY 10012 (Virgiliu.Midrigan@nyu.edu). Acknowledgements: We thank Jonathan Eaton and Rob Johnson for helpful comments. David Richards provided excellent research assistance.

${ }^{1}$ For a study of global trade flows see Rudolfs Bems, Robert Johnson, and Kei-Mu Yi (2010) and Jonathan Eaton et al. (2010).

${ }^{2}$ We measure industrial production (IP) as a trade-weighted average of durable and non-durable IP. It thus controls for major compositional differences between trade and production.

${ }^{3}$ For example, Davin Chor and Kalina Manova (2010) and Mary Amiti and David Weinstein (2009) attribute part of the decline in trade to the cost of finance for international transactions rising by more than for domestic transactions.
}

are more severe than for domestic transactions, leading firms involved in international trade to hold a much larger stock of inventories. We document these facts, using plant-level data, in our earlier work. Following a persistent negative shock to costs or demand, firms - especially those involved in international transactions - find themselves with too much inventory on hand and thus cut back sharply on ordering, selling out of the existing stock. Intuitively, since, by definition, imports (production) are equal to sales plus inventory investment, and both sales and inventory investment decline during a recession, imports (production) are more volatile than sales. Moreover, since importers hold larger stocks of inventories than domestic firms, the response of imports is much larger than that of production.

In Alessandria, Kaboski and Midrigan (2010b) we study a general equilibrium twocountry model of international trade in which firms face fixed costs of exporting and a stockout-avoidance motive for holding inventories. The model, when parameterized to match the evidence on the inventory holding premium of importers, is capable of accounting for the salient features of the dynamics of trade in the recent recession. In particular, the model predicts a response of imports that is much larger than that of domestic sales or production.

Our goal here is to present empirical evidence consistent with the view that the magnified dynamics of trade are, to a large extent, shaped by inventories. In particular, we show that the fluctuations in trade in the current recession were not unusual relative to the size of fluctuations of other macroeconomic variables. What is unusual is the depth of the recession. The similarity of current trade dynamics with those in previous recessions calls for an explanation of the recent trade collapse that is about the nature of trade, rather than the source of the business cycle. Next, using data from the auto industry, a sector for which we have measures of both inventories and sales of imported cars, we illus- 
trate the role of inventories. For autos we find that about two-thirds of the peak decline in imports in the auto sector can be attributed to firms running down their stocks rather than a fall in final sales of autos. Similarly, trade only recovered when inventory levels had stabilized. Finally, we present evidence that a sizable fraction of the unexplained movements, or "wedges," in trade both in the current recession and over time are accounted for by changes in inventories.

\section{Response of trade in recent recession was not unusual}

Figure 1 depicts the recent deviations of U.S. imports, exports, and several other macroeconomic variables from a Hodrick-Prescott (1600) trend. From the third quarter of 2007 to the second quarter of 2009 GDP $(Y)$ fell by about 5 percent relative to trend, while industrial production (IP) and a trade-weighted measure of final expenditure on goods (Demand) each fell by about 13 percent. In contrast, the collapse in trade was much more severe: exports and imports fell by around 20 percent. Although these numbers are striking, we argue below that the recent decline in trade (relative to the decline in other macroeconomic aggregates) was not unusual relative to past recessions.

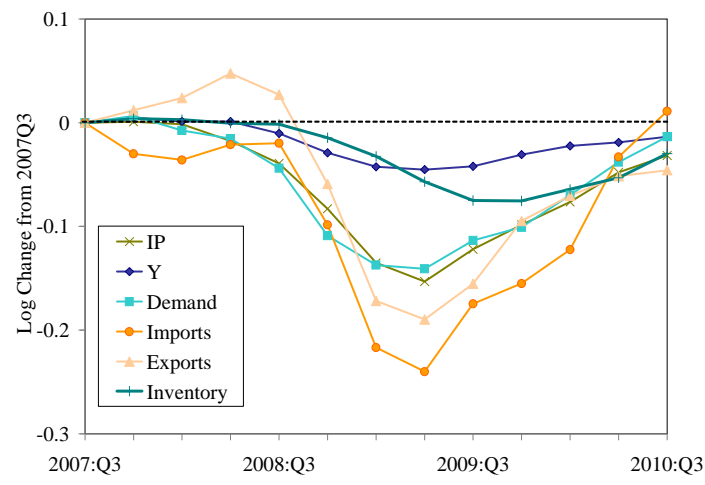

Figure 1: Recent U.S. Aggregate Dynamics

Table 1 reports the characteristics of some measures of aggregate activity (GDP, IP, and tradeweighted expenditure) in the current and previous recessions. In the first two columns, we report a trade elasticity as the change in the log of imports or exports relative to the change in the log of each respective variable. The change is computed from peak-to-trough. The last col- umn reports the relative volatility of imports and exports over the entire sample, measured as the ratio of each series' standard deviation.

Table 1: Trade Dynamics

\begin{tabular}{cccc}
\hline \hline & \multicolumn{2}{c}{ Peak-to-Trough Elasticity } & \multirow{2}{*}{$\begin{array}{c}\text { Relative } \\
\text { Volatility }\end{array}$} \\
\cline { 2 - 3 } & 2009Q2 & Median & \\
\hline IMPORTS & & & 3.8 \\
GDP & 5.3 & 4.7 & 1.6 \\
IP & 1.6 & 1.6 & 1.8 \\
Demand & 1.7 & 2.4 & \\
EXPORTS & & & 3.4 \\
GDP & 5.2 & 3.3 & 1.5 \\
IP & 1.5 & 1.5 & \\
\hline \hline
\end{tabular}

Notes: Data are from 1967q1 to 2010q3, Trade and GDP from BEA. IP is from the Federal Reserve. Each series is HP-filtered with a smoothing parameter of 1600 .

Table 1 shows that imports fell about 5 times more than GDP, twice as much as expenditures on tradeable goods and about 60 percent more than industrial production. Most importantly, compared to the median U.S. recession, the fall in imports in the current (2009Q2 column) recession does not look unusual. For exports, our findings are similar.

The last column of Table 1 shows that our conclusions are not driven by our focus on recessions, rather than business cycle fluctuations in general. We note that exports and imports are roughly 50 and 60 percent more volatile than industrial production, around 3.5 times more volatile than GDP, and around 60 and 80 percent more volatile than expenditure on tradeables. Finally, while not reported in the table, exports and imports are also more volatile than consumption, as well as consumption of durable goods (exports and imports are 1.2 and 1.4 times more volatile than durable goods consumption). ${ }^{4}$ We thus conclude that the excess volatility of international trade does not simply reflect the fact that trade is more intensive in durable goods. ${ }^{5}$

\footnotetext{
${ }^{4}$ We have also studied more disaggregate measures of trade flows and production and generally find that trade is more volatile than either production or sales of the same goods. These results are discussed in the online appendix.

${ }^{5}$ Martin Boileau (1999) and Charles Engel and Jian Wang (2011) attribute the volatility of trade to trade being intensive in cyclical goods like capital equipment or durables. Bems, Johnson, and Yi (2010) and Eaton, et al. (2010) show that a large part of the global fall in trade relative to GDP can be accounted for by this composition mismatch.
} 


\section{Evidence for auto industry}

The challenge in isolating the role of inventories in the dynamics of international trade is the lack of data on inventories of imported goods at either the industry or aggregate level. The auto industry is an exception as U.S. data exists on inventories, sales, and imports of foreignproduced autos. We use these data to show that inventory adjustment was an important determinant of the collapse of international trade in autos. These data also alleviate concerns that the fall in trade relative to expenditures or production is attributed to the composition of trade differing from production or expenditure.

The evidence on autos is, we argue, important in its own right, since autos are an important traded good, accounting for 18 percent of U.S. non-petroleum imports from 2005 to 2007. Moreover, the drop in auto imports was much steeper than that for other goods: the decline in auto imports alone accounted for about one-third of the fall of U.S. imports in this episode. Any explanation of the recent trade collapse must also be able to explain autos to have any chance at explaining aggregates more generally.

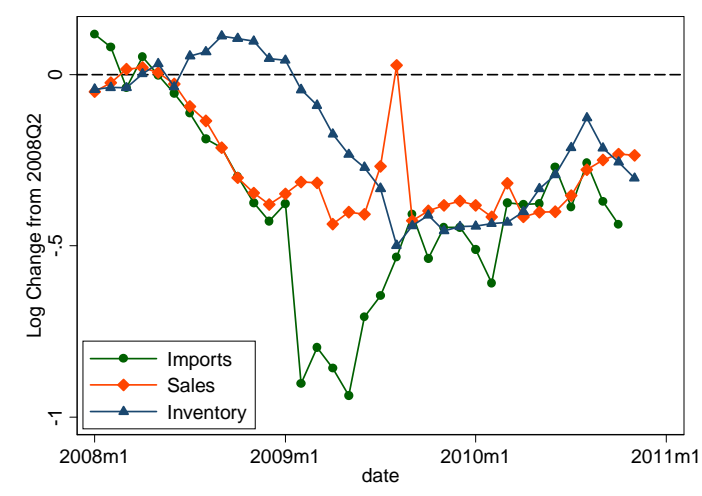

Figure 2: Dynamics of Foreign Autos

Figure 2 plots the evolution of imports, sales, and inventories of autos produced outside North America since 2008. At its worst, over the 7 months from February 2009 to August 2009, real imports and sales were, respectively, on average $77 \log$ points and 30 log points below their 2008Q2 averages. ${ }^{6}$ Thus for autos, the drop in imports over this period was over 2.5 times the

\footnotetext{
${ }^{6}$ The abrupt, mid-figure, upward spike in sales is the Car Rebate Allowance System (i.e., “cash for clunkers”) program.
}

drop in sales. Since, by definition, imports are equal to sales plus inventory investment, the evidence in Figure 2 suggests that inventory adjustment accounted for about two-thirds of the drop in imports. Additionally, we see that the recovery in trade did not result from a persistent increase in final sales of autos, but rather from the stabilizing of inventory holdings. These import and sale dynamics are similar for other countries and during previous recessions (see Alessandria, Kaboski and Midrigan, 2010b), and, since these data do not suffer from a mismatch between the composition of imports and absorption, they provide very strong evidence for a high elasticity of imports.

\section{Aggregate evidence}

We next explore the role of inventories in aggregate trade fluctuations by measuring the departures in trade flows from those predicted by theory. This approach involves deriving a simplified aggregate import demand equation, calibrating its parameters, and then measuring deviations from predicted imports given fundamentals. Andrei Levchenko, Logan Lewis, and Linda Tesar (2010) use this approach to document large deviations in trade flows, $m_{t}^{D}$, from the predictions of the theory, $m_{t}^{T}$. These deviations, or wedges, in import demand might be interpreted as changes in trade barriers. We show, however, that inventory adjustment is important for both the magnitude and the interpretation of these wedges.

To motivate our analysis, consider the following accounting identity:

$$
M_{t}=S_{t}+I_{t}-I_{t-1},
$$

where $M_{t}$ are imports, $S_{t}$ are sales of imported goods, and $I_{t}$ is the inventory stock of imported goods so that $I_{t}-I_{t-1}$ is inventory investment. We also assume a constant elasticity demand for imported goods:

$$
S_{t}=P_{t}^{-\gamma} C_{t},
$$

where $P_{t}$ is the relative price of imports and $C_{t}$ is aggregate absorption. Equation (1) is an accounting identity, while (2) characterizes a large class of models of international trade.

We assume that in the long-run sales of foreign goods equals imports, $\bar{S}=\bar{M}$, so that in- 
ventory investment, is zero. Then we have:

$$
\frac{M_{t}-\bar{M}}{\bar{M}}=\frac{S_{t}-\bar{S}}{\bar{S}}+\frac{\bar{I}}{\bar{S}} \frac{I_{t}-I_{t-1}}{\bar{I}},
$$

where $\bar{I}$ is the long-run stock of inventories and $\bar{I} / \bar{S}$ is the inventory-to-sales ratio. Combining (2) and (3), using a log approximation for small deviations, and letting lower-case variables denote log-deviations from trend, yields:

$$
m_{t}^{T}=-\gamma p_{t}+c_{t}+\frac{\bar{I}}{\bar{S}}\left(i_{t}-i_{t-1}\right)
$$

We obtain a standard Armington demand equation by setting inventory adjustment to zero:

$$
\hat{m}_{t}^{T}=-\gamma p_{t}+c_{t}
$$

Assuming a conventional value of the Armington elasticity of $\gamma=1$, we can contrast the timeseries of U.S. imports with those predicted by the theory and define $\hat{\omega}_{t}=m_{t}^{D}-\hat{m}_{t}^{T}$ as the implied trade wedge when ignoring inventory adjustment. Similarly, we define $\omega_{t}=m_{t}^{D}-m_{t}^{T}$ as the wedge predicted by a theory that allows for inventory adjustment. We measure $p_{t}$ as the ratio of the non-petroleum import price index relative to a price index on final expenditures of goods. Our measure of aggregate expenditure, $C_{t}$, is domestic expenditures on goods and investment.

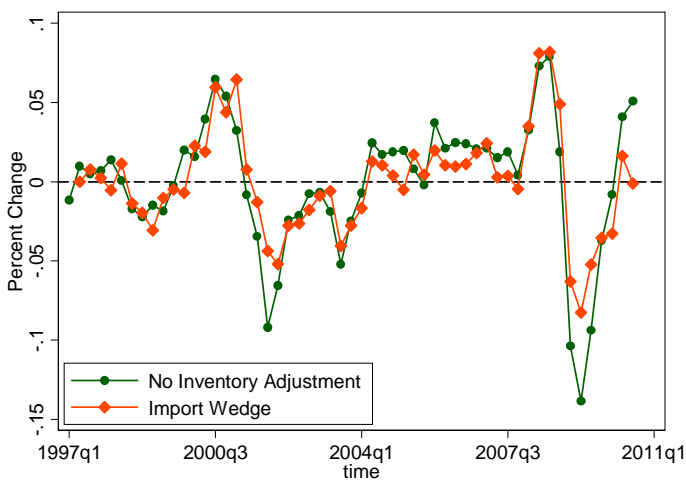

Figure 3: Wedges

Figure 3 plots the evolution of this wedge without the inventory adjustment since 1997q1, measured as deviations from a Hodrick-Prescott (1600) trend. In this past recession, the wedge declines by almost 15 percent, and thus accounts for about two-thirds of the drop in trade. Moreover, the wedge in this current recession appears quite large compared to previous fluctuations (roughly 15 percent versus 5 to 10 percent in previous declines). By these measures, the behavior of imports appears quite unusual given the movements in expenditure and relative prices.

We next explore how inventory fluctuations affect the magnitude of the wedge. Comparing (3) with (4), the actual import wedge subtracts out inventory adjustment from the implied wedge, $\omega_{t}=\hat{\omega}_{t}-(\bar{I} / \bar{S})\left(i_{t}-i_{t-1}\right)$.

To measure the import wedge then requires a measure of the inventory-to-sales ratio of imported goods as well as the changes in imported inventory. Unlike autos, we lack direct measures of imported inventories and thus use the entire stock of U.S. inventories as a proxy. Consistent with the micro evidence in Alessandria, Kaboski and Midrigan (2010a) that importers hold about double the inventory of non-importers, we set $\bar{I} / \bar{S}$ equal to 2.25 , about twice the average inventory-to-sales ratio since 1997 . We assume that fluctuations in imported inventories are perfectly correlated with fluctuations in aggregate inventories.

Figure 3 shows that fluctuations in the actual import wedge, $\omega_{t}$, are generally smaller than fluctuations in the wedge that ignores inventory adjustments, $\hat{\omega}_{t}$. Indeed, in the current recession, nearly one-third of the decline and all of the increase in our first measure of the wedge disappears and the size of the import wedge appears less unusual. Thus, inventory adjustments made a sizable contribution to recent trade fluctuations.

To quantify the contribution of inventory investment, we calculate the fraction of the variance of the wedge without the inventory adjustment, $\hat{\omega}_{t}$, that is accounted for by inventory investment. Given our lack of data on the stock of imported inventory, we consider a range of inventory-to-sales ratios for importers, $\bar{I} / \bar{S}$, equal to 1.12 and 2.25, and also several different values of the Armington elasticity, $\gamma$. As Table 3 shows, with an importer-specific inventory-tosales ratio of 2.25, the inventory term accounts for 30 to 49 percent of the trade wedge from the simple Armington import demand equation. This is substantial, since this result is likely biased downward due to our imperfect mea- 
sure of importers' inventories. ${ }^{7}$ If we lower the inventory-to-sales ratio to an economy-wide 1.12, the value for the U.S. (mainly reflecting domestic goods), the contribution of inventories falls some, to between 10 to 33 percent, but is still substantial. ${ }^{8}$

Table 2: Inventories' Contribution to Import Wedge

\begin{tabular}{ccc}
\hline \hline Armington & Inventory-Sales Ratio (I/S) \\
Elasticity $(\gamma)$ & 1.12 & 2.25 \\
\hline 0 & 0.33 & 0.49 \\
1 & 0.23 & 0.38 \\
2 & 0.10 & 0.30 \\
\hline \hline
\end{tabular}

Notes: Using HP-filtered data from 1997:q1 to 2010:q3. Contribution equals 1 - variance $\left(\omega_{t}\right) / \operatorname{variance}\left(\hat{\omega}_{t}\right)$.

\section{Conclusions}

We have presented evidence that international trade fluctuated more than economic activity in the recent recession, and that inventories have played an important role in these fluctuations. While we have focused on the recent recession, these empirical phenomena appear relevant more generally, both across U.S. recessions and across countries.

Our results have implications for future work. With the magnified response of trade they generate, inventory considerations for storable goods may influence the international transmission of business cycles. For example, the massive drop in U.S. auto sales together with large inventory holdings led to a sharp contraction in the production of exports for the U.S. in Japan, roughly 2.5 times the drop in sales. Inventories held outside of Japan may therefore have contributed to the severity of Japan's recession. We are currently exploring this idea in Alessandria, Kaboski, and Midrigan (2011). On the micro side, the growing availability of plant- and transaction-level

\footnotetext{
${ }^{7}$ Focusing on a longer period starting in 1972q2, the contribution of inventory adjustments is smaller, ranging between 19 to 46 percent. We conjecture that aggregate inventories are a much worse proxy for imported inventories in this earlier period, since relative price movements were more important, and imports were a smaller share of absorption.

${ }^{8}$ An alternative approach to evaluate the contibution of inventory dynamics on trade flows is to estimate the import demand equation derived above. This regression is normally run in first differences and omits an inventory term. We found that including this inventory term substantially increases the $R^{2}$ fit of these regressions.
}

datasets should enable detailed and precise examination of how inventory considerations affect the timing and level of trade, especially international trade. In a more globally integrated world, with inputs from and sales to distant markets, inventories and inventory management are becoming an ever more critical element in the production and sales process.

\section{REFERENCES}

Alessandria, George, Joseph P. Kaboski, and Virgiliu Midrigan. 2010a. "Inventories, Lumpy Trade, and Large Devaluations," American Economic Review, 100(5): 2304-39

Alessandria, George, Joseph P. Kaboski, and Virgiliu Midrigan. 2010b. "The Great Trade Collapse of 2008-09: An Inventory Adjustment?” IMF Economic Review, 58(2): 25494

Alessandria, George, Joseph P. Kaboski, and Virgiliu Midrigan. 2011. "Inventories and International Business Cycles.” mimeo.

Amiti, Mary and David Weinstein. 2009. "Exports and Financial Shocks." NBER working paper 15556.

Bems, Rudolfs, Robert C. Johnson, and KeiMu Yi. 2010, "The Role of Vertical Linkages in the Propagation of the Global Downturn of 2008," IMF Economic Review, 58(2): 295-326.

Boileau, Martin. 1999. "Trade in Capital Goods and the Volatility of Net Exports and the Terms of Trade," Journal of International Economics, 48(2): 347-65.

Chor, Davin and Manova, Kalina. 2010. “Off the Cliff and Back: Credit Conditions and International Trade During the Global Financial Crisis.” NBER Working Paper 16174.

Eaton, Jonathan, Samuel Kortum, Brent Neiman, and John Romalis. 2010. "Trade and the Global Recession.” mimeo.

Engel, Charles, and Jian Wang. 2011. "International Trade in Durable Goods: Understanding Volatility, Cyclicality, and Elasticities,” Journal of International Economics, 83(1): 3752.

Levchenko, Andrei A., Logan T. Lewis and Linda L. Tesar. 2010. "The Collapse of International Trade During the 2008-2009 Crisis: In Search of the Smoking Gun," IMF Economic Review, 58(2): 214-53. 